Classification

Physics Abstracts

$61.80 \mathrm{~J}-64.75-81.30 \mathrm{M}$

\title{
Effects of atomic collisions on rubidium clusters embedded into $\mathrm{MgO}$ crystals
}

\author{
M. Treilleux and P. Thévenard \\ Département de Physique des Matériaux $\left({ }^{*}\right)$, Université Claude Bernard-Lyon I, \\ 43, boulevard du 11 novembre 1918, 69622 Villeurbanne Cedex, France
}

(Reçu le 2 mai 1984, révisé le 14 novembre, accepté le 21 décembre 1984)

\begin{abstract}
Résumé. - Des monocristaux de $\mathrm{MgO}$, préimplantés avec des ions rubidium et ensuite recuits, contiennent des petits précipités de rubidium bien caractérisés par mesures d'absorption optique et microscopie électronique en transmission. Des mesures d'absorption optique ont montré que durant la réimplantation avec des ions $\mathrm{Rb}^{+}$le nombre de précipités diminue avec la dose : la phase précipitée a totalement disparue pour une dose égale à $7 \times 10^{14}$ ions. $\mathrm{cm}^{-2}$. Ces effets semblent être associés à un processus de collisions atomiques.

Abstract. - $\mathrm{MgO}$ single crystals, preimplanted with rubidium ions and subsequently annealed, contain small rubidium precipitates which have been well characterized by optical absorption measurements and transmission electron microscopy. Optical absorption measurements have shown that during the reimplantation with $\mathrm{Rb}^{+}$ions the number of precipitates decreases with the fluence : the precipitated phase has completely disappeared for a fluence of $7 \times 10^{14}$ ions. $\mathrm{cm}^{-2}$. These effects seem to be associated with an atomic collision process.
\end{abstract}

\section{Introduction.}

Optical absorption of $\mathrm{MgO}$, implanted with alkali ions [1-3] shows two absorption bands located at $250 \mathrm{~nm}$ and $575 \mathrm{~nm}$, which correspond to anionic vacancies ( $F$ type centres) and cationic vacancies ( $V$ type centres) respectively. Even for high fluences the optical spectra do not reveal the presence of alkali atoms.

Subsequent annealing performed on these samples lead to the disappearing of intrinsic point defects ( $\mathrm{F}$ and $\mathrm{V}$ type centres) as also the aggregation of a part of the implanted atoms. Then an optical absorption band due to plasma oscillation of free electrons in metallic precipitates of alkali metal embedded in the $\mathrm{MgO}$ matrix is observed in the spectra.

In this paper, we report on the evolution of $\mathrm{MgO}$ crystals implanted with $\mathrm{Rb}^{+}$ions. The purpose of this work is to investigate the effects of ion beam on small metallic precipitates of rubidium embedded into an insulating matrix $\mathrm{MgO}$. Fortunately, the optical absorption due to metallic precipitates depends on the number of precipitated atoms [4], thus, the evolution of this band is directly connected with the evolution of the precipitated phase.

As the maximum energy transferred in a nuclear collision is obtained when projectiles and target atoms have the same mass, the implantations have been performed with rubidium ions.

(*) L.A. CNRS, № 172 . 


\section{Experimental procedure.}

$\mathrm{MgO}$ crystals (4N purity) cleaved into (100) platelets of dimensions $12 \times 12 \times 0.3 \mathrm{~mm}^{3}$ were obtained from W. C. Spicer Ltd. Implantations were performed, using a Balzers implantor for low energies ( $\leqslant 200 \mathrm{keV}$ ), and a $2.5 \mathrm{MeV}$ Van de Graaff accelerator for high energies. The bombarded target area was $1 \mathrm{~cm}^{2}$. The crystals implanted at high energies were annealed in air whereas the other ones were annealed under vacuum in order to prevent oxidation of aggregates. The optical absorption spectra were recorded using a Cary 17 double beam spectrophotometer. For in situ analysis during implantation a Beckman DK 2A spectrophotometer was used. Classical transmission electron microscopy (T.E.M.) observations were carried out with a $100 \mathrm{keV}$ Philips EM 300.

\section{Experimental results.}

3.1 Thermal evolution of MgO CRystals Implanted With a High Fluence OF $\mathrm{Rb}^{+}$IONS. Figure 1 shows the optical absorption spectrum of a $\mathrm{MgO}$ crystal implanted at low energy $(170 \mathrm{keV})$ with $\mathrm{Rb}^{+}$ions. As expected, this spectrum only exhibits the two bands, at 250 and $575 \mathrm{~nm}$, due to intrinsic defects ( $\mathrm{F}$ and $\mathrm{V}$ type centres).

Thermal annealings performed on this sample lead to the decrease of these band amplitudes. After a $950 \mathrm{~K}$ anneal these bands have completely disappeared and a broad band located at about $850 \mathrm{~nm}$ appears in the spectrum. According to the Doyle theory [4], this optical absorption band should be due to plasma oscillations of free electrons in small rubidium precipitates embedded into the $\mathrm{MgO}$ matrix. The energy at which this absorption occurs is given by :

$$
\hbar \omega=\hbar \omega_{\mathrm{p}}\left(1+2 n_{0}^{2}\right)^{-1 / 2}
$$

where $\hbar \omega_{\mathrm{p}}$ is the plasmon energy of free electrons in the bulk metal (3.65 eV for rubidium) and $n_{0}$

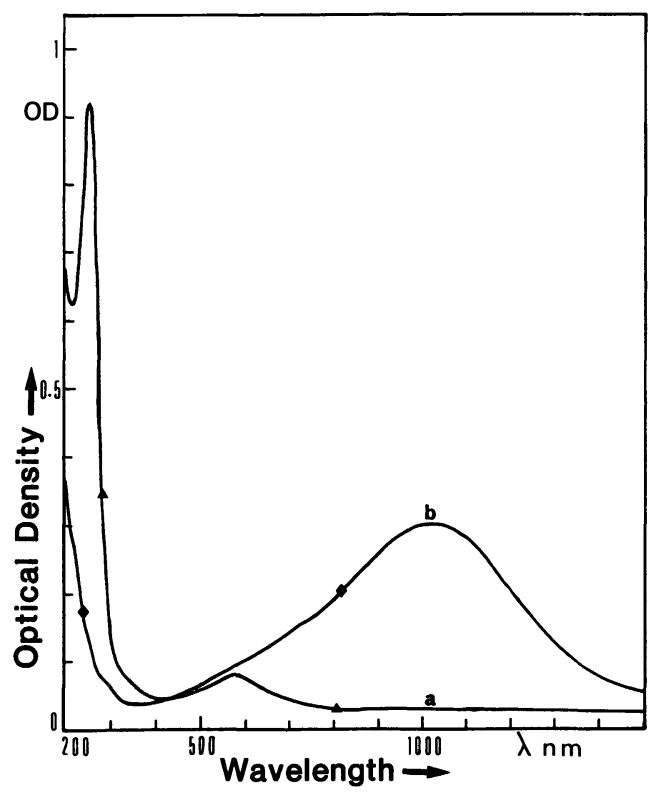

Fig. 1. - Optical absorption spectra of $\mathrm{MgO}$ implanted with $2 \times 10^{16} \mathrm{~cm}^{-2} \mathrm{Rb}^{+}$ions of $170 \mathrm{keV}$ energy ; (a) as implanted, (b) annealed under vacuum for $15 \mathrm{~min}$ at $1023 \mathrm{~K}$. 
the refractive index of the $\mathrm{MgO}$ matrix $\left(n_{0}=1.73\right)$. Then the calculated energy position of this absorption band is $1.38 \mathrm{eV}(\lambda \simeq 900 \mathrm{~nm})$ which is very close to the experimental value $: 1.46 \mathrm{eV}$ $(\lambda \simeq 850 \mathrm{~nm})$. The amplitude of this band increases with increasing temperature and its maximum shifts towards larger wavelengths. This evolution seems to be characteristic of the precipitation of implanted atoms into small metallic clusters $[5,6]$. As expected, after anneal at $1023 \mathrm{~K}$, the optical absorption band shifts towards larger wavelength : $1030 \mathrm{~nm}$ (Fig. 1).

The size distribution of the precipitates cannot be deduced from the optical absorption band. However, when the size of precipitates is small compared with the mean free path of electrons in the bulk metal, assuming a sharp size distribution around the mean radius $\bar{r}$, the full width at half maximum of the absorption band $\Delta E_{1 / 2}$ is related to the mean radius by the formula [4] :

$$
\Delta E_{1 / 2}=h \frac{v_{\mathrm{F}}}{\bar{r}}
$$

where $h$ is the Planck constant and $v_{\mathrm{F}}$ the Fermi velocity of electrons.

Considering the experimental value $\left(\Delta E_{1 / 2}=0.61 \mathrm{eV}\right)$ deduced from the optical absorption band and the Fermi velocity $\left(v_{\mathrm{F}}=0.81 \times 10^{6} \mathrm{~m} \cdot \mathrm{s}^{-1}\right)$, the mean radius of precipitates $\bar{r}$ is about $5.5 \mathrm{~nm}$.

These precipitates of rubidium in $\mathrm{MgO}$ lattice have been clearly characterized using transmission electron microscopy. Figure 2 shows a large precipitate of rubidium and the corresponding diffraction pattern indicating precipitate reflections.

3.2 EFFECTS OF ATOMIC COLlision IN MgO CRYSTALS CONTAINING RUBIDIUM PRECIPITATES. The $\mathrm{MgO}$ sample was implanted with $5 \times 10^{16} \mathrm{~cm}^{-2} 2 \mathrm{MeV} \mathrm{Rb^{+ }}$ ions. The electronic and nuclear energy losses of $2 \mathrm{MeV} \mathrm{Rb}^{+}$ions in $\mathrm{MgO}$, calculated from the L.S.S. theory [7] are reported in figure $3 \mathrm{a}$. The range-energy relation, deduced from these two curves is nearly linear for energies lower than $2 \mathrm{MeV}$ (Fig. 3a). As shown in this figure, the mean projected range $R_{\mathrm{p}}$ of $2 \mathrm{MeV}$ rubidium ions in $\mathrm{MgO}$ is about $670 \mathrm{~nm}$. The range straggling $\Delta R_{\mathrm{p}}$ calculated from the Dearnaley et al. tables [8] is about $135 \mathrm{~nm}$. Assuming a Gaussian distribution in depth for the implanted particles, we have plotted in figure $3 \mathrm{~b}$ the concentration of rubidium atoms versus the depth for a fluence of $5 \times 10^{16} \mathrm{Rb}^{+} . \mathrm{cm}^{-2}$. The maximum concentration is about $1.6 \times 10^{21} \mathrm{Rb}^{+} . \mathrm{cm}^{-3}$, which corresponds to approximately 3 foreign atoms per $100 \mathrm{Mg}$ or $\mathrm{O}$ atoms.

The optical absorption spectrum of this sample annealed for $15 \mathrm{~min}$ at $1173 \mathrm{~K}$, exhibits a band at $850 \mathrm{~nm}(1.46 \mathrm{eV})$ associated with rubidium precipitates and a bump at a shorter wavelength : $560 \mathrm{~nm}(2.21 \mathrm{eV})$ (Fig. 4). A similı bump together with the principal optical absorption band associated with metallic precipitates was observed in the case of $\mathrm{MgO}$ crystals implanted with $\mathrm{Li}^{+}, \mathrm{Na}^{+}$and $\mathrm{K}^{+}$and subsequently annealed [1,9], and also in additively coloured alkali halides [10-12].
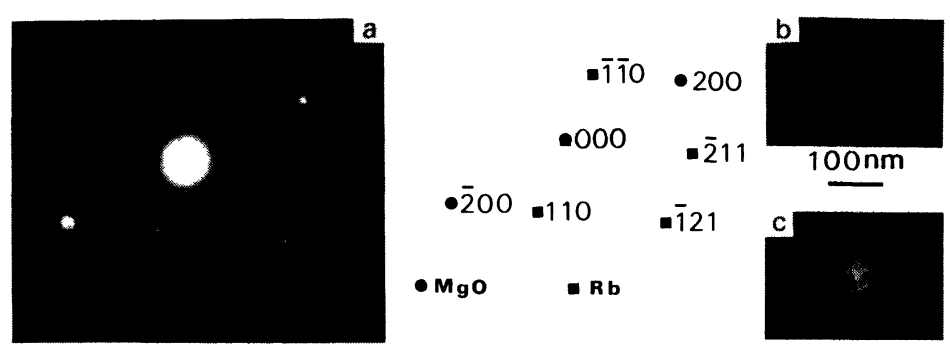

Fig. 2. - $\mathrm{MgO}$ implanted with $4 \times 10^{16} \mathrm{~cm}^{-2} 150 \mathrm{keV} \mathrm{Rb}^{+}$ions and subsequently vacuum annealed for $15 \mathrm{~min}$ at $1073 \mathrm{~K}$. (a) Diffraction pattern on a large precipitate $:(\overline{113}) \mathrm{Rb}$; (b) bright field image of the $\mathrm{Rb}$ precipitate; (c) dark field image of the $\mathrm{Rb}$ precipitate using $(\overline{1} \overline{1} 0)^{*}$ precipitate reflection. 

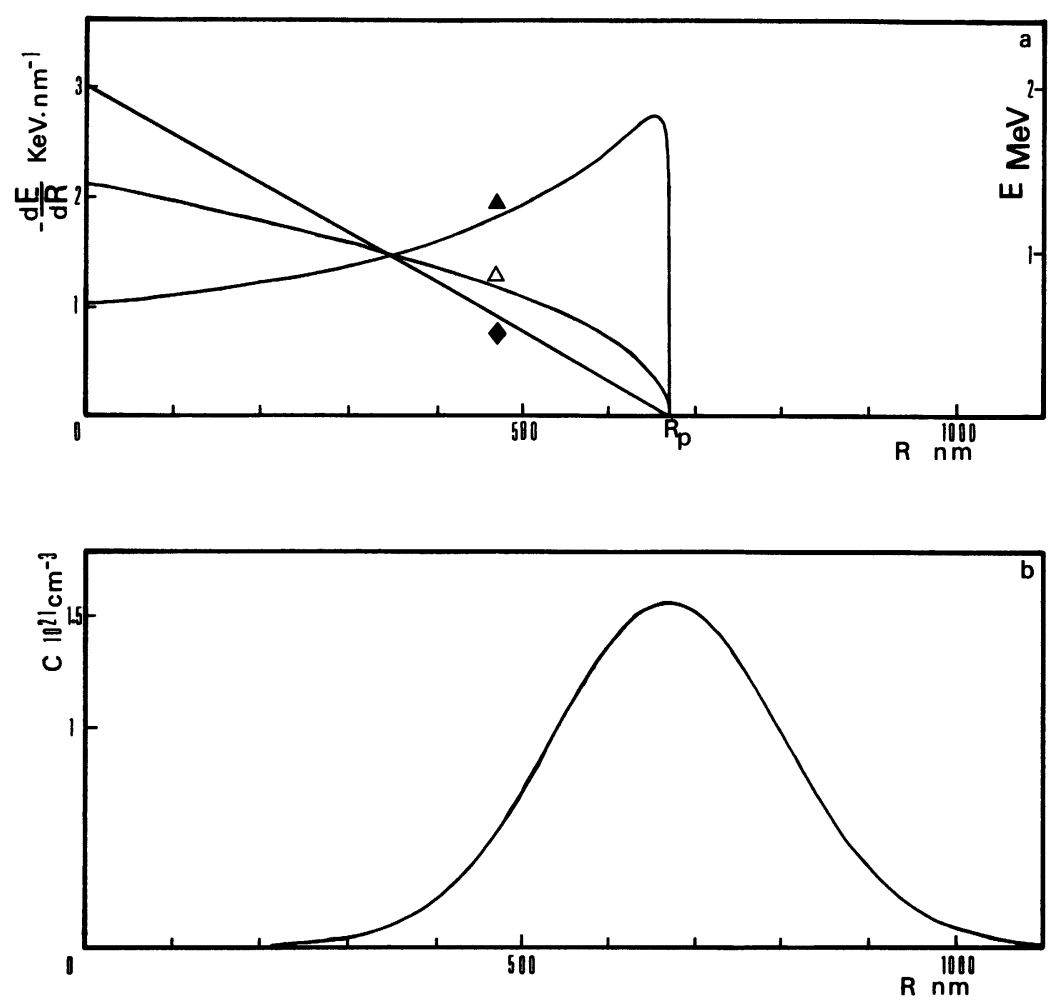

Fig. 3. - (a) Theoretical results of L.S.S. for the slowing down of $2 \mathrm{MeV} \mathrm{Rb^{+ }}$ ions incident on a $\mathrm{MgO}$ target : stopping power $(-\mathrm{d} E / \mathrm{d} R)$ for electronic $(\Delta)$ and nuclear $(\Delta)$ processes for the " average " particle; $(\diamond)$ range energy relation. (b) Distribution of the concentration $C$ of $\mathrm{Rb}$ atoms versus the depth $R$ for $5 \times 10^{16} \mathrm{~cm}^{-2} \mathrm{Rb}^{+}$ions of $2 \mathrm{MeV}$ energy.

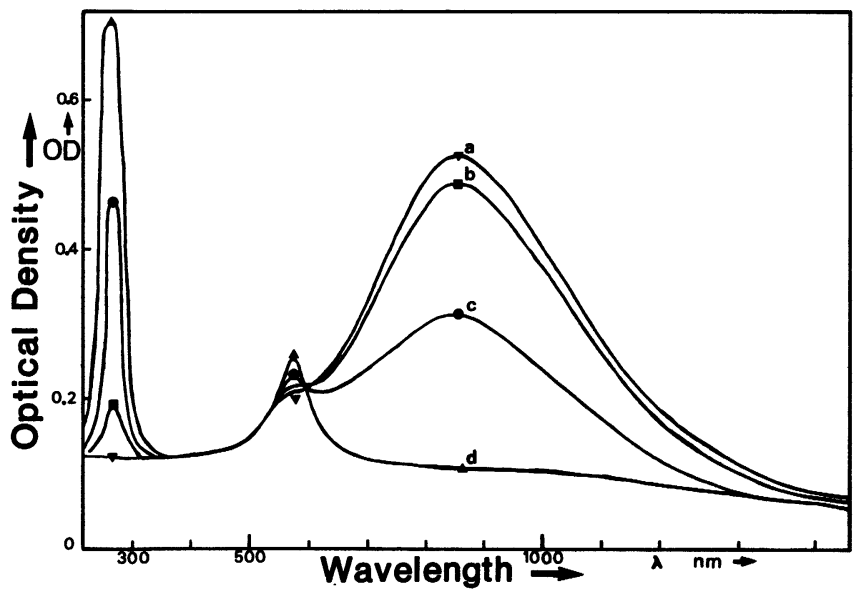

Fig. 4. - Optical absorption spectra of MgO implanted with $5 \times 10^{16} \mathrm{~cm}^{-2} \mathrm{Rb}^{+}$ions of $2 \mathrm{MeV}$ energy annealed for $15 \mathrm{~min}$ at $1173 \mathrm{~K}$ : (a) as annealed; (b) $5 \times 10^{12} \mathrm{Rb}^{+} \mathrm{cm}^{-2}$ reimplantation; (c) $4.5 \times$ $10^{13} \mathrm{Rb}^{+} \mathrm{cm}^{-2}$ reimplantation; (d) $7 \times 10^{14} \mathrm{Rb}^{+} \mathrm{cm}^{-2}$ reimplantation. 
The mean size of rubidium precipitates, deduced from the principal optical absorption band, is about $10 \mathrm{~nm}$ (Fig. 4).

This crystal was implanted, at a low dose rate $\left(5 \times 10^{11}\right.$ ions. $\left.\mathrm{cm}^{-2} \mathrm{~s}^{-1}\right)$, with the same $2 \mathrm{MeV}$ $\mathrm{Rb}^{+}$ions and the optical absorption spectra were recorded in situ after each dose. Figure 4 shows the evolution of the optical absorption spectrum of this sample. The amplitude of the $850 \mathrm{~nm}$ $(1.46 \mathrm{eV})$ optical absorption band, due to $\mathrm{Rb}$ precipitates, decreases with the fluence. Up to $7 \times 10^{14} \mathrm{Rb}^{+} \mathrm{cm}^{-2}$, this band fully vanished. Simultaneously to this evolution a band at $250 \mathrm{~nm}$ appears and the bump near $560 \mathrm{~nm}$ increases. The $250 \mathrm{~nm}$ absorption band is associated with $\mathrm{F}$ type centres; its amplitude increases fastly with the fluence. Concerning the absorption spectra evolution near $560 \mathrm{~nm}$, it results from the contribution of two previously discussed bands, one corresponding to the bump at $560 \mathrm{~nm}$ and the other one at $575 \mathrm{~nm}$ associated with $\mathrm{V}$ type centres. As the amplitude of the principal optical absorption band $(850 \mathrm{~nm})$ decreases during bombardment, the amplitude of the bump associated with this band should decrease. On the contrary the amplitude increase of the bump $(560 \mathrm{~nm})$ observed on the spectra, simultaneously with the one of the band associated with the $F$ type centres suggests that the contribution of $V$ type centres to the evolution of this bump is preponderant.

The main result of this experiment is the evolution of the principal optical absorption band $(850 \mathrm{~nm})$ versus the fluence. As the area under the optical absorption band associated with precipitates is proportional to the number of $\mathrm{Rb}$ atoms precipitated $[4,6]$, the decrease of this area (Fig. 4) indicates a destruction of $\mathrm{Rb}$ precipitates during bombardment. The same evolution was observed in $\mathrm{MgO}$ crystals containing sodium aggregates implanted with $\mathrm{Na}^{+}$ions, and the destruction of Na precipitates confirmed by T.E.M. observations [13]. However, the decrease of the absorption band area due to metallic precipitates was of $40 \%$ for $4.5 \times 10^{13} \mathrm{Rb}^{+} . \mathrm{cm}^{-2}$ whereas it was only of $30 \%$ for $3 \times 10^{14} \mathrm{Na}^{+} . \mathrm{cm}^{-2}$. The cross section relative to the destruction of precipitates is thus higher for the heaviest ion $\left(\mathrm{Rb}^{+}\right)$showing the preponderant effect of atomic collisions.

\section{Discussion and conclusion.}

Small metallic precipitates embedded into an insulating matrix $(\mathrm{MgO})$ can be destroyed by irradiation with energetic particles. Two processes can produce this aggregate destruction : ionization and elastic collisions. In the region containing the precipitates, the linear nuclear and electronic energy losses of $\mathrm{Rb}^{+}$ions are high $\left(2.8 \mathrm{keV} . \mathrm{nm}^{-1}\right.$ and $0.8 \mathrm{keV} . \mathrm{nm}^{-1}$ respectively). Therefore the two processes could be responsible for this destruction.

In order to determine which one of these processes is preponderant, we have bombarded a $\mathrm{MgO}$ crystal containing $\mathrm{Rb}$ precipitates with $2 \mathrm{MeV}$ protons. With such particles, the energy losses, in the region containing the precipitates, are mainly electronic. After irradiation with $9 \times 10^{16}$ protons. $\mathrm{cm}^{-2}$ the precipitates are not destroyed : no modification occurs in the optical absorption band associated with rubidium aggregates. The linear electronic energy loss of protons in the region containing the precipitates is about $0.04 \mathrm{keV} . \mathrm{nm}^{-1}$. Assuming an homogeneous dissipated energy in the crystal volume containing the aggregates the energy dissipated by electronic process in this region is approximately $3.6 \times 10^{22} \mathrm{keV} . \mathrm{cm}^{-3}$ for $9 \times 10^{16}$ protons. $\mathrm{cm}^{-2}$ of $2 \mathrm{MeV}$ energy. This value is higher than the one obtained for $7 \times 10^{14} \mathrm{Rb}^{+} \mathrm{cm}^{-2}$ of $2 \mathrm{MeV}$ energy which is about $5.6 \times 10^{21} \mathrm{keV} . \mathrm{cm}^{-3}$. These results, clearly indicate that the ionization process is not responsible for the metallic precipitate destruction. They are in agreement with the observations of defect production in $\mathrm{MgO}$ and metals $[8,14]$. In these materials, defects are not created by an ionization process.

In conclusion, considering the effects of $\mathrm{Rb}^{+}$ion bombardment on small $\mathrm{Rb}$ precipitates embedded into $\mathrm{MgO}$, the precipitate destruction seems to be closely related to the nuclear energy losses of the particles in the region containing the aggregates and then to an atomic collision process. 


\section{References}

[1] Thevenard, P., J. Physique Colloq. 37 (1976) C7-526.

[2] Treilleux, M., Thevenard, P., Chassagne, G. and Hobbs, L. W., Phys. Status Solidi 48 (1978) 425.

[3] Treilleux, M. and Chassagne, G., J. Physique Lett. 40 (1979) L-283.

[4] Doyle, W. T., Phys. Rev. 111 (1958) 1067.

[5] Compton, W. D., Phys. Rev. 107 (1957) 1271.

[6] Mie, G., Ann. Phys. 25 (1908) 377.

[7] Lindhard, J., Scharff, M. and Schiott, H. E., K. Dan. Vidensk. Selsk. Mat. Fys. Meddn. 33 (1963) 14.

[8] Dearnaley, G., Freeman, J. H., Nelson, R. S. and Stephen, J. H., Ion implantation (North-Holland, Amsterdam) 1973, 766-777.

[9] Marichy, G., Chassagne, G. and Durand, D., Phys. Status Solidi 92 (1979) 221.

[10] Gans, R., Annalen Phys. 37 (1912) 881.

[11] Fuchs, R., Phys. Rev. B. 11 (1975) 1732.

[12] JAIN, S. C. and Hughes, A. E., J. Mater. Sci. 13 (1978) 1611.

[13] Thevenard, P., Treilleux, M., Ruault, M. O., Chaumont, J. and Bernas, H., Nucl. Instrum. Methods B 1 (1984) 235.

[14] Evans, B. D., Comas, J. and Malmberg, P. R., Phys. Rev. B 6 (1972) 2453. 